\title{
Wnt signalling in adenomas of familial adenomatous polyposis patients
}

\author{
GM Caldwell',', CE Jones', AM Ashley', W Wei', RK Hejmadi', DG Morton' and GM Matthews' \\ 'School of Cancer Sciences, The University of Birmingham, Edgbaston, Birmingham, BI5 2TH, UK
}

\begin{abstract}
BACKGROUND: Epigenetic silencing of Wnt antagonists and expression changes in genes associated with Wnt response pathways occur in early sporadic colorectal tumourigenesis, indicating that tumour cells are more sensitive to Wnt growth factors and respond differently. In this study, we have investigated whether similar changes occur in key markers of the Wnt response pathways in the genetic form of the disease, familial adenomatous polyposis (FAP).

METHODS: We investigated epigenetic and expression changes using pyrosequencing and real-time RT-PCR in samples from seven patients without neoplasia, and matched normal and tumour tissues from 22 sporadic adenoma and I4 FAP patients.

RESULTS: We found that 17 out of 24 (7I\%) FAP adenomas were hypermethylated at sFRPI, compared with 20 out of 22 (9I\%) of sporadic cases. This was reflected at the level of sFRPI transcription, where $73 \%$ of FAP and $100 \%$ of sporadic cases were downregulated. Increased expression levels of c-myc and FZD3 were less common in FAP (35 and 46\% respectively) than sporadic tumours (78 and 67\% respectively).

CONCLUSION: Overall, the changes in expression and methylation were comparable, although the degree of change was generally lower in the FAP adenomas. Molecular heterogeneity between multiple adenomas from individual FAP patients may reflect different developmental fates for these premalignant tumours.

British Journal of Cancer (2010) I 03, 910-917. doi:10.1038/sj.bjc.6605790 www.bjcancer.com
\end{abstract}

Published online 13 July 2010

(c) 2010 Cancer Research UK

Keywords: colorectal cancer; FAP; Wnt signalling

Loss of $A P C$ gene activity is a common event in sporadic colorectal tumourigenesis, occurring in about $80 \%$ of cases (Morin et al, 1997). Germ-line mutation of the APC gene causes familial adenomatous polyposis (FAP) and this, along with mice carrying similar mutations, has been investigated extensively as a paradigm for sporadic disease (Fearnhead et al, 2001).

The majority of sporadic colorectal dysplasia and malignancy require inactivation of the APC gene, promoting $\beta$-catenin/TCF4mediated transcription. Because APC functions within the Wnt $/ \beta$ catenin arm of the Wnt signalling pathway, it may be expected that changes in these pathways and their actions associated with tumourigenesis would be similar in both genetic and sporadic diseases.

Previous studies have identified two further frequent Wnt pathway changes in sporadic tumours. First, secreted Wnt antagonists, both the sFRP family and the structurally unrelated WIF-1, are silenced epigenetically (Caldwell et al, 2004; Suzuki et al, 2004; He et al, 2005). These are $\beta$-catenin-responsive genes (Caldwell et al, 2006): in the absence of epigenetic silencing, APC mutation and consequent $\beta$-catenin action would lead to Wnt antagonist induction in a negative feedback loop (Caldwell et al, 2008), starving the tumour cell of Wnt ligand. Because Wnt deprivation of primary tumour cells in culture leads to apoptosis (He et al, 2005), this silencing may be necessary for survival of the early tumour.

*Correspondence: Dr GM Caldwell; E-mail: G.M.Caldwell@bham.ac.uk Received 9 April 2010; revised 17 June 2010; accepted 17 June 2010; published online 13 July 2010
The second Wnt-associated change observed in early sporadic tumours is a re-organisation of the Wnt response pathways away from $\beta$-catenin responses and towards the less well-characterised $\beta$-catenin-independent outcomes (Caldwell et al, 2008). These include changes in FZD receptor profiles and high-level induction of NKD1, which effectively diverts Wnt ligand-derived signals away from $\beta$-catenin and towards Wnt/PCP outcomes (Yan et al, 2001). In normal epithelia, these changes most likely represent transient negative feedback responses that desensitise the cell to high levels of Wnt ligands but their sustained expression in tumour cells may contribute to the tumourigenic process. Although the spectrum of outcomes has yet to be characterised, one result of Wnt/PCP signalling is c-jun phosphorylation, an essential step in colorectal tumourigenesis (Nateri et al, 2005).

Studies in FAP tissues and $\mathrm{Apc}^{\text {min }}$ mice could advance our understanding of the Wnt pathway changes observed in sporadic tumours. A number of studies using tissue from FAP patients have failed to show nuclear localisation of $\beta$-catenin in early adenomas with mild dysplasia, unlike sporadic adenomas (Anderson et al, 2002; Bläker et al, 2003; Phelps et al, 2009), which raises questions about the sequence of events following APC loss in FAP. Interestingly a recent article by Obrador-Hevia et al (2010) showed increased nuclear staining of $\beta$-catenin in FAP adenomas which correlated with larger size (adenomas $>1 \mathrm{~cm}$ ) and biallelic APC inactivation. Early changes in Wnt signalling pathways may provide targets for cancer prevention. A similar profile of changes must occur in FAP for it to be used as a model system to evaluate such therapies. Similarly, differences in changes in the Wnt signalling components between sporadic and genetic disease may further our understanding of the key mutational events in the 
development of this common tumour. We therefore set out to examine key components of the Wnt signalling pathways in FAP adenomas and compare any alterations with those found in sporadic cases.

\section{MATERIALS AND METHODS}

\section{Patient samples}

Sporadic adenoma samples were identified from our tumour bank from patients more than 50 years of age and without a family history of colorectal cancer. All tumour samples were collected from the sigmoid colon or the rectum and matched control rectal biopsies were taken at the same procedure $(5 \mathrm{~cm}$ or more from the tumour site). Familial adenomatous polyposis adenoma and matched control samples were taken from patients with a proven diagnosis of FAP. Normal unaffected control samples were taken from patients with no gastrointestinal malignancy. A summary of the clinical characteristics of each sample group can be found in Table 1. Samples were collected according to local ethical committee regulations, with individual consent from each patient for molecular studies.

\section{Quantitative real-time RT-PCR}

Total RNA was extracted from the patient samples using TRI Reagent (Sigma, Poole, UK) and $0.5 \mu$ g total RNA was converted to cDNA using a High Capacity cDNA Reverse Transcription Kit (Applera, Warrington, UK). Oligonucleotide primers and TaqMan probe sequences are shown in Tables 1 and 2. Multiplex polymerase chain reaction (PCR) amplifications were performed using an ABI PRISM 7500 Sequence Detector (Warrington,

Table I Summary of the clinical features of the three sample groups (normal unaffected, sporadic disease and FAP patients)

\begin{tabular}{|c|c|c|c|c|c|c|c|}
\hline Sample group & Sex (M/F) & $\begin{array}{c}\text { Median age } \\
\text { in years (range) }\end{array}$ & $\begin{array}{c}\text { Total } \\
\text { biopsy no. }\end{array}$ & $\begin{array}{l}\text { Site of biopsy - } \\
\text { right/left side } \\
\text { of colon (ND) }\end{array}$ & $\begin{array}{l}\text { Median size of adenoma } \\
\text { in } \mathrm{mm} \text { (range) }\end{array}$ & $\begin{array}{l}\text { Pathology } \\
\text { (TA/TVA) }\end{array}$ & $\begin{array}{c}\text { Grade of dysplasia } \\
\text { (low/high) }\end{array}$ \\
\hline Normal & $6 / 1$ & $60(35-68)$ & 12 control & $1 / 11$ & - & - & - \\
\hline Sporadic & $12 / 10$ & $65(56-79)$ & 22 control & $0 / 22$ & - & - & - \\
\hline Disease & & & 22 adenoma & $|/ 2|$ & $10(5-30)$ & $10 / 12$ & $19 / 3$ \\
\hline FAP patients & $9 / 9$ & $24(18-38)$ & 18 control & $9 / 7(6)$ & - & - & - \\
\hline
\end{tabular}

Abbreviations: $\mathrm{M}=$ male; $\mathrm{F}=$ female; $\mathrm{TA}=$ tubular adenoma; $\mathrm{ND}=$ not documented; TVA = tubular villus adenoma. Right-sided adenomas are taken between the rectum and splenic flexure, left-sided adenomas are from the transverse colon to the caecum.

Table 2 Detailed information on the FAP adenoma samples used in the methylation and expression analyses

\begin{tabular}{|c|c|c|c|c|c|c|c|c|}
\hline FAP adenoma & Expr & Meth & Sex M/F & $\begin{array}{l}\text { Age in } \\
\text { years }\end{array}$ & $\begin{array}{l}\text { Site of biopsy - right/left } \\
\text { side of colon (ND) }\end{array}$ & $\begin{array}{c}\text { Size of } \\
\text { adenoma }(\mathrm{mm})\end{array}$ & $\begin{array}{l}\text { Pathology } \\
\text { (TA/TVA) }\end{array}$ & $\begin{array}{c}\text { Grade of dysplasia } \\
\text { (low/high) }\end{array}$ \\
\hline la & Y & Y & $\mathrm{F}$ & 32 & L & 2 & TA & Low \\
\hline $\mathrm{lb}$ & Y & Y & & & L & 2 & TA & Low \\
\hline Id & $Y$ & Y & & & L & 2 & TA & Low \\
\hline $2 \mathrm{a}$ & Y & $\mathrm{N}$ & $\mathrm{F}$ & 29 & $\mathrm{R}$ & 5 & TA & Low \\
\hline $2 b$ & $Y$ & $\mathrm{~N}$ & & & L & 5 & TA & Low \\
\hline $3 b$ & $Y$ & Y & & & $\mathrm{R}$ & 5 & TVA & High \\
\hline $3 c$ & Y & Y & & & L & 35 & TA & Low \\
\hline $4 a$ & $Y$ & $\mathrm{~N}$ & $\mathrm{~F}$ & 26 & $\mathrm{R}$ & 6 & TA & Low \\
\hline $4 b$ & $Y$ & $\mathrm{~N}$ & & & L & 9 & TA & Low \\
\hline $5 a$ & $Y$ & $Y$ & $\mathrm{~F}$ & 26 & $\mathrm{R}$ & 3 & TA & Low \\
\hline $5 b$ & $Y$ & Y & & & $R$ & 3 & TA & Low \\
\hline $6 a$ & $Y$ & $\mathrm{~N}$ & $M$ & 21 & ND & 2 & TA & Low \\
\hline $1 \mathrm{lb}$ & $Y$ & $Y$ & & & $\mathrm{R}$ & 2 & TA & Low \\
\hline IIc & Y & Y & & & L & 2 & TA & Low \\
\hline $1 / d$ & $Y$ & Y & & & L & 3 & TA & Low \\
\hline $12 \mathrm{a}$ & $Y$ & Y & $M$ & 38 & L & 2 & TA & Low \\
\hline $13 a$ & $Y$ & $Y$ & $\mathrm{~F}$ & 27 & ND & 5 & TA & Low \\
\hline $14 a$ & $Y$ & Y & $\mathrm{F}$ & 35 & L & 10 & TA & Low \\
\hline 15 & $\mathrm{~N}$ & Y & $\mathrm{F}$ & 25 & ND & 5 & TA & Low \\
\hline 16 & $\mathrm{~N}$ & $Y$ & $M$ & 18 & $L$ & 10 & TA & Low \\
\hline 17 & $\mathrm{~N}$ & Y & $M$ & 18 & $R$ & 5 & TA & Low \\
\hline 18 & $N$ & $Y$ & $M$ & 19 & $\mathrm{~L}$ & 7 & TA & Low \\
\hline
\end{tabular}

Abbreviations: $\mathrm{ND}=$ not documented; $\mathrm{FAP}=$ familial adenomatous polyposis; Expr $=\mathrm{mRNA}$ expression analysis performed; Meth = methylation analysis performed; $\mathrm{M}=$ male; $\mathrm{F}=$ female; $\mathrm{TA}=$ tubular adenoma; TVA = tubular villus adenoma. 
Cheshire, UK) in a final volume of $15 \mu$ l. Each reaction contained $1 \times$ qPCR Mastermix (Eurogentec, Aylesbury, UK), $90 \mathrm{~nm} \mathrm{KRT8}$ and target gene primers, $150 \mathrm{~nm}$ target gene TaqMan probe, and $175 \mathrm{~nm}$ KRT8 TaqMan probe and $1 \mu \mathrm{l}$ of cDNA. Cycling conditions were an initial step at $50^{\circ} \mathrm{C}$ for $2 \mathrm{~min}$ and $95^{\circ} \mathrm{C}$ for $10 \mathrm{~min}$, followed by 40 cycles at $95^{\circ} \mathrm{C}$ for $15 \mathrm{~s}$ and $60^{\circ} \mathrm{C}$ for $1 \mathrm{~min}$. Results from the human target genes were normalised to the epithelial-cell-specific gene keratin 8 (KRT8) (Table 3).

\section{Analysis of DNA methylation status using bisulphite/ pyrosequencing}

Bisulphite treatment of $1 \mu \mathrm{g}$ genomic DNA was carried out using the EpiTect Bisulfite Kit (Qiagen, Crawley, UK) following the manufacturer's recommendations. Primers adapted from the sFRP1 combined bisulphite restriction analysis (COBRA) assay previously described by our laboratory (Caldwell et al, 2004) were used to amplify $1 \mu \mathrm{l}$ of bisulphite-treated DNA. The primary PCR reaction product was diluted 100 -fold and $1 \mu \mathrm{l}$ of this was added to a $50 \mu \mathrm{l}$ reaction containing $10 \mathrm{pmol}$ COBRA-F primer and $5 \mathrm{pmol}$ biotin-labelled COBRA-Rnest. Each reaction was amplified using a touchdown PCR; $94^{\circ} \mathrm{C}$ for $3 \mathrm{~min} ; 20$ cycles of $94^{\circ} \mathrm{C}$ for $10 \mathrm{~s}$, $66-0.5^{\circ} \mathrm{C}$ for $20 \mathrm{~s}, 72^{\circ} \mathrm{C}$ for $30 \mathrm{~s} ; 20$ cycles of $94^{\circ} \mathrm{C}$ for $10 \mathrm{~s}, 56^{\circ} \mathrm{C}$ for $20 \mathrm{~s}, 72^{\circ} \mathrm{C}$ for $30 \mathrm{~s}$ and finally $72^{\circ} \mathrm{C}$ for $5 \mathrm{~min}$. After PCR, the products were captured on streptavidin-coated beads and incubated with $10 \mathrm{pmol}$ of sequencing primer (COBRA-Fnest). Pyrosequencing was performed using PyroMark Gold Q96 reagents and a PyroMark Q96 MD pyrosequencing machine (Qiagen). This assay measures the methylation status of seven $\mathrm{CpG}$ sites at positions $+318,+321,+344,+351,+353,+357$ and +370 relative to the $s F R P 1$ translation start site. CpG sites were hypermethylated if methylation was greater than $63 \%$, this cutoff value corresponds to the average methylation in normal tissue +2 times the standard deviation (s.d.) as described previously (Chung et al, 2008).

\section{Immunohistochemistry}

The streptavidin-biotin indirect immunoperoxidase method was performed as described previously (Hardy et al, 2002). Sections $(5 \mu \mathrm{m})$ were dewaxed and re-hydrated, then endogenous peroxidase activity was blocked by incubation with $10 \% \mathrm{H}_{2} \mathrm{O}_{2}$ in methanol for $30 \mathrm{~min}$. Microwave antigen-retrieval was undertaken for both antibodies. Sections were incubated overnight with a primary antibody recognising phospho-c-jun (ser63-P; Santa Cruz Biotechnology, Heidelberg, Germany) at a dilution of $1: 400$, diluted in $20 \%$ normal goat serum. After washing with PBS, sections were incubated with biotinylated goat anti-mouse/rabbit IgG (Dako, Ely, UK) according to the manufacturer's instructions for $30 \mathrm{~min}$. Serial PBS washing and incubation with streptavidin peroxidase conjugate (Dako) was undertaken before incubation with diaminobenzidine tetrahydrochloride (Sigma-Aldrich, Gillingham, UK). Sections were counterstained with haematoxylin (BDH Laboratory Supplies, Poole, UK), dehydrated and analysed on a light microscope.

\section{Statistical methods}

Wilcoxon's signed-rank test was performed using R (http://www. r-project.org/). $P$-values $<0.05$ were considered as significant. Pearson's correlation coefficient $(r)$ was calculated as a measure of the strength of the association between the two continuous variables. An $r$ value $>0.7$ was considered statistically significant.

\section{RESULTS}

\section{Methylation status of sFRP1 promoter}

Our previous studies have shown hypermethylation of the $s F R P 1$ gene at the earliest stages of sporadic colorectal tumourigenesis (Caldwell et al, 2006). To determine whether hypermethylation of sFRP1 occurs in the large bowel mucosa and adenomas in FAP, we measured the methylation status of seven $\mathrm{CpG}$ sites close to the transcription start site of sFRP1. Samples from 14 patients with FAP (21 normal colon mucosa and 24 adenomas), 22 patients with sporadic adenomas (22 normal colon mucosa and 22 adenomas) and 7 patients without large bowel neoplasia (11 normal colon mucosa) were examined by bisulphite pyrosequencing. These results are summarised in Figure 1.

An average methylation score for each $\mathrm{CpG}$ site was calculated for the FAP patients where multiple control and adenoma samples were available (Table 2). Analysis of the data using the Wilcoxon's signed-rank test shows that $s F R P 1$ is significantly more methylated in adenoma compared with matched normal colonic mucosa in both FAP and sporadic patients (Table 4). The data show that while significant methylation changes occur at $\mathrm{CpG}$ sites 3 and 4 in FAP $(P=0.03)$, they occur at all seven sites in sporadic disease $(P=0.003)$

Normal colonic mucosa from healthy controls and patients with sporadic disease was found to have a comparable degree of methylation, with only small differences observed between individual CpG sites (Figure 1). Only 1 out of 11 normal control samples showed methylation above $63 \%$ (black circle) and in only 1 out of the $7 \mathrm{CpG}$ sites. In contrast, 10 out of 21 of the normal

Table 3 Sequences of primers used in real-time RT-PCR analysis

\begin{tabular}{|c|c|c|}
\hline & Assay type & Primers \\
\hline \multicolumn{3}{|l|}{ Human PCR assays } \\
\hline \multirow[t]{3}{*}{ sFRPI (NM_0030I2) } & TaqMan & F, 5'-CCAATCCCACCGAAGCCT-3' \\
\hline & & R, 5'-ATGATGGCCTCAGATITCAACTC-3' \\
\hline & & P, 5'-CAAGCCCCAAGGCACAACGGTG-3' \\
\hline \multirow[t]{3}{*}{ NKD / (NM_033|19) } & TaqMan & F, 5'-TCGCCGGGATAGAAAACTACA-3' \\
\hline & & R, 5'-CAGTTCTGACTTCTGGGCCAC-3' \\
\hline & & P, 5'-CCAATTTGGGCCTGGCTCCCC-3' \\
\hline \multirow[t]{3}{*}{ FZD3 (NM_0I74I2) } & TaqMan & F, 5'-CATGGAGATGTTTGGTGTTCCTT-3' \\
\hline & & R, 5'-AAGTCGAGGATATGGCTCATCAC-3' \\
\hline & & P, 5'-TCTGGGAACCTACTGCATTCCATATCTTCAGG-3' \\
\hline \multirow[t]{3}{*}{ c-myc (NM_002467) } & TaqMan & F, 5'-AGCTGCTTAGACGCTGGATTाT-3' \\
\hline & & R, 5'-TTCCTGTTGGTGAAGCTAACGTT-3' \\
\hline & & P, 5'-CAGCCTCCCGCGACGATGC-3' \\
\hline \multirow[t]{3}{*}{ KRT8 (NM_002273) } & TaqMan & F, 5'-GATCGCCACCTACAGGAAGCT-3' \\
\hline & & R, 5'-ACTCATGTTCTGCATCCCAGACT-3' \\
\hline & & P, 5'-CCGGCTCTCCTCGCCCTCCA-3' \\
\hline
\end{tabular}



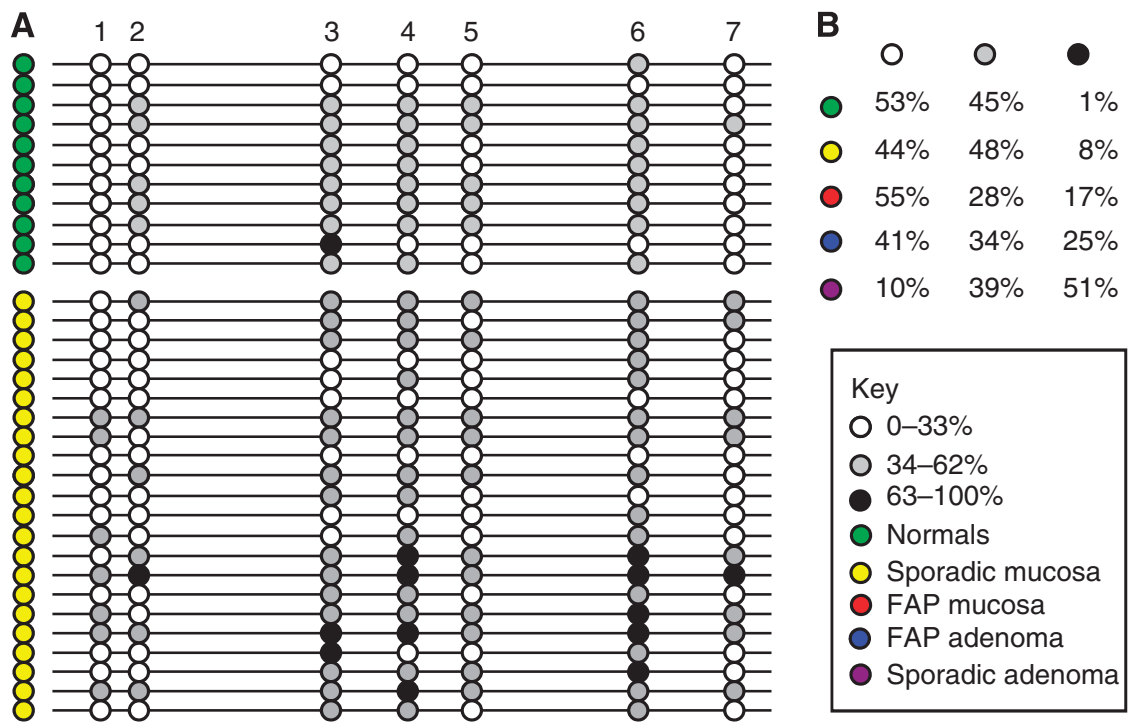

\begin{tabular}{|l|}
\hline Key \\
$0-33 \%$ \\
$034-62 \%$ \\
$63-100 \%$ \\
0 Normals \\
O Sporadic mucosa \\
O FAP mucosa \\
O FAP adenoma \\
Sporadic adenoma
\end{tabular}


Figure I Bisulphite-pyrosequencing analysis of sFRPI gene methylation. (A) Pictorial representation of the percentage methylation of seven CpG sites within the first exon of the sFRPI gene. The average methylation in normal tissue was calculated as 33\%, CpG sites with less than $33 \%$ methylation are shown as white circles. Fully methylated (above the cut-off) samples corresponded to average methylation in normal tissue +2 times the standard deviation (s.d.) as described previously (Chung et al, 2008), these are shown as black circles (>63\% methylation). Grey circles represent 34-62\% methylation. Five sample groups are represented (normal unaffected samples (green), FAP normal mucosa (red), sporadic normal mucosa (yellow), FAP adenomas (blue) and sporadic adenomas (purple)). The FAP normal tissue shows an increase in methylation (more black circles) compared with unaffected and sporadic normal tissue. Both FAP and sporadic adenomas had increased methylation compared with the normal samples. (B) The table summarises the data in panel $\mathbf{A}$ as the percentage number of samples within each group with methylation 0-33\% (white), 34-62\% (grey) and >63\% (black). 
Table 4 -values (Wilcoxon's rank-sum test) of methylation at each of the seven CpG sites tested in sFRPI in adenoma vs matched normal mucosa in both FAP and sporadic patients

\begin{tabular}{lcc}
\hline CpG site & FAP $(\boldsymbol{n}=\mathbf{1 4})$ & Sporadic $(\boldsymbol{n}=\mathbf{1 9})$ \\
\hline 1 & 0.217 & 0.007 \\
2 & 0.367 & 0.006 \\
3 & 0.075 & 0.007 \\
4 & 0.096 & 0.016 \\
5 & 0.451 & 0.005 \\
6 & 0.975 & 0.016 \\
7 & 0.221 & 0.015 \\
Average of site 3 and 4 & 0.030 & 0.010 \\
Average of site 1 to 7 & 0.119 & 0.003 \\
\hline
\end{tabular}

Abbreviation: $F A P=$ familial adenomatous polyposis.

colon samples from FAP patients show methylation of $63 \%$ or greater at one or more $\mathrm{CpG}$ sites.

Adenoma samples from both FAP and sporadic patients showed increased methylation compared with matched normal mucosa. The sporadic adenomas showed the greatest degree of methylation. $90 \%$ of the CpG sites examined in sporadic adenomas were methylated compared with $59 \%$ in the FAP adenomas. This is particularly striking when examining the median methylation value for each $\mathrm{CpG}$ site (data not shown). The sporadic adenomas range from 51 to $70 \%$ methylation compared with a range of 25 to $61 \%$ methylation in the FAP adenomas. The data showed a greater level of methylation in FAP adenomas compared with matched normal mucosal biopsies at all CpG sites examined showing that methylation is a frequent and early event in FAP tumourigenesis although at a lower level than that observed in sporadic disease.

\section{mRNA expression profile of the Wnt antagonist $s F R P 1$}

Our previous studies identified loss of SFRP1 expression at the premalignant stage of colorectal cancer development (Caldwell et al, 2006). To assess whether this is also seen in FAP-related tumourigenesis and whether the epigenetic changes identified in FAP were influencing expression, we measured mRNA levels using quantitative real-time RT-PCR. In total 26 adenomas taken from a cohort of 14 FAP patients aged between 18 and 38 years, and 9 sporadic adenomas taken from patients aged between 59 and 65 years were analysed. In each case the adenoma expression levels were compared with expression levels in normal bowel mucosa taken from the same patient as previously described (Caldwell et al, 2004). The results are summarised in Figure 2.

Both the FAP and sporadic adenomas showed a similar trend of down-regulation of sFRP1 expression. Of 26, 19 (73\%) FAP adenomas and all of the sporadic adenomas showed a greater than 4 -fold down-regulation of SFRP1. The magnitude of change was different, with sporadic adenomas showing greater downregulation (median -973-fold, IQR -263 to -2990 ) than the FAP adenomas (median -7.2 -fold, IQR -3 to -44 ).

The widespread down-regulation of $s F R P 1$ in FAP cases corresponds with the epigenetic changes in sporadic adenomas in this and our previous study. The level of $s F R P 1$ methylation observed in FAP and sporadic adenomas reflects the degree of suppression of $s F R P 1$ expression, indicating it is causative. These data show epigenetic suppression of $s F R P 1$ to be a common and early event and are consistent with this being a requirement for the development of FAP and sporadic large bowel neoplasia.

\section{mRNA expression profile of $\beta$-catenin transcription target genes, $N K D 1$ and $c-m y c$}

To assess whether the $S F R P 1$ changes in FAP and sporadic colorectal adenomas reflected a modification of $\beta$-catenin transcriptional activity, we measured the expression levels of two $\beta$-catenin target genes, NKD1 and $c-m y c$, using quantitative real-time RT-PCR.

NKD1 expression was up-regulated ( $>4$-fold) in 19 out of 26 FAP adenomas and all 9 sporadic adenomas. The magnitude of up-regulation differed between the groups with sporadic adenomas showing nearly a 20 -fold greater effect (Figure 2). A reduction in NKD1 expression was observed in two FAP adenomas (2a and 6a) compared with their matched normal tissue.

$c-m y c$ was up-regulated ( $>4$-fold) in 7 out of $9(78 \%)$ sporadic adenomas and 9 out of 26 (35\%) FAP adenomas. The nine FAP adenomas with increased $c-m y c$ also had increased levels of NKD1. In FAP sample $1 \mathrm{a}$ and $11 \mathrm{c}$ and sporadic samples 1 and $7, c-m y c$ levels are reduced whereas NKD1 is induced, suggesting other factors may be affecting $c-m y c$ expression.

\section{Evidence of Wnt pathway re-organisation in FAP adenomas}

FZD3 induction Our recent study (Caldwell et al, 2008) showed that Wnt response pathways are re-organised in early colorectal tumourigenesis: NKD1 induction is accompanied by up-regulation of the $\beta$-catenin-independent receptors FZD3 and 6. Unlike NKD1, however, FZD3/6 do not respond to stabilisation of $\beta$-catenin in vitro and require a Wnt ligand signal. FZD3/6 may, therefore, provide an indication of the degree of Wnt ligand signalling in the tumour.

We therefore measured $F Z D$ transcript levels in the two series of adenomas. Figure 2 shows that FZD3 was induced by a factor of $>4$ in 6 of 9 sporadic adenomas and 12 of the 26 FAP specimens, suggesting a broadly similar incidence of Wnt response pathway re-organisation between the two groups.

The inter-quartile ranges of FZD3 induction in the sporadic and FAP adenoma groups (3-17 vs 1.0-26) showed much greater similarity than a similar comparison for NKD1 (79-1053 vs 2-62).

An interesting observation in this study was the different expression profiles between different adenomas taken from the same FAP patient (see patients 1,2 and 11, Figure 2). In sporadic adenomas the down-regulation of $s F R P 1$ correlates directly with an up-regulation of NKD1, but this is not always the case in the FAP adenomas. For instance in adenomas $2 \mathrm{a}$ and $6 \mathrm{a} s F R P 1$ and NKD1 are both down-regulated and in adenoma $8 \mathrm{a} s F R P 1$ is downregulated but there is no change in NKD1 expression.

c-jun phosphorylation We previously reported a correlation between Wnt response pathway re-organisation and phosphorylation of c-jun, an outcome of Wnt/PCP signalling, in sporadic adenomas (Caldwell et al, 2008). To investigate whether this occurs in FAP, we stained paraffin sections from 11 of the FAP patients to analyse for nuclear phosphorylated c-jun and examples of this are shown in Figure 3. Adenomas from these patients had also been analysed for mRNA expression of $\beta$-catenin transcription target genes (sFRP1, NKD1 and $c-m y c)$ and the FZD 3 receptor.

Nuclear phospho-c-jun was observed in the majority, 9 out of 11 FAP adenomas. Fresh frozen tissue was available for mRNA analysis in the two FAP patient samples (patients 5 and 12), which stained negative for nuclear phospho-c-jun. Interestingly, patient 12 showed no change in $s F R P 1$ expression but did demonstrate induction of NKD1, c-myc and FZD3. Patient 5 showed a more typical molecular profile, that is, down-regulation of $s F R P 1$ and up-regulation of NKD1 and FZD3 although $c$-myc was unchanged. This suggests that in FAP, Wnt/PCP signalling is not the only factor involved in c-jun activation.

\section{DISCUSSION}

These data show considerable similarity between expression of Wnt components measured in premalignant sporadic and FAP 
A



Figure 2 Real-time RT-PCR quantitation of relative mRNA expression in a series of 26 matched colorectal FAP tumours and 9 matched sporadic colorectal tumours according to the comparative $C_{T}$ method as previously described (Caldwell et al, 2004). The inset shows the median and inter-quartile ranges (IQR) of expression levels for each gene in FAP/sporadic adenomas. A, sFRPI; B, NKDI; C, c-myc; D, FZD3. The sample numbers correspond to individual FAP patients and details of each adenoma can be found in Table 2.

large bowel adenomas. We have presented evidence to suggest the magnitude of these events may be greater in sporadic disease. These results are consistent with these changes involved in neoplastic development and/or stabilisation.

Age-related methylation of $s F R P 1$ has been reported (Konishi et $a l, 2007)$. One clear distinction between sporadic and FAP tumours is the age of the host: all the sporadic adenomas in this study were from patients more than 56 years of age whereas FAP adenomas were collected from colonectomies performed on patients between 18 and 38 years of age. The impact of these age differences on rates of APC mutation and somatic hypermethylation is difficult to estimate: if methylation were purely stochastic, it would be reasonable to expect it to have a greater impact in older hosts, however in this study we have shown hypermethylation in tissue from a young population, which have been associated with the development of neoplasia. Interestingly $17 \%$ of the CpG sites in the younger FAP normal samples were fully methylated compared with $8 \%$ in sporadic and only $1 \%$ in unaffected normal samples (Figure 1B). It is possible that this is a result of contamination due to the difficulty in sampling 'normal' colonic mucosa from FAP patients but a recent report by Obrador-Hevia et al (2010) showed abnormal expression of $c-m y c$ and repression of $s F R P 1$ in macroscopically normal mucosa in patients with FAP, suggesting Wnt signalling pathway changes occur very early in FAPassociated tumourigenesis.

Most FAP adenomas showed qualitative changes that were similar to sporadic tumours. In those cases where $\beta$-catenin target genes were up-regulated, the degree of induction was comparable to that observed in sporadic adenomas, but the degree of $s F R P 1$ suppression in FAP adenomas was smaller than in sporadic cases. This could be the result of pre-existing change in the matched normal mucosa, but the raw $\Delta C_{\mathrm{t}}$ data (not shown) do not indicate this. Although $s F R P 1$ gene hypermethylation is normally associated with complete silencing in sporadic adenomas, the lower levels of methylation observed in FAP adenomas appear to reflect partial suppression of gene expression. The outcome of this, or whatever other mechanisms are involved, is that FAP adenomas show significant reductions in sFRP1 transcription compared with matched normal mucosa, despite their elevated $\beta$-catenin activity. If Wnt ligand signalling is required for adenoma formation, it may 

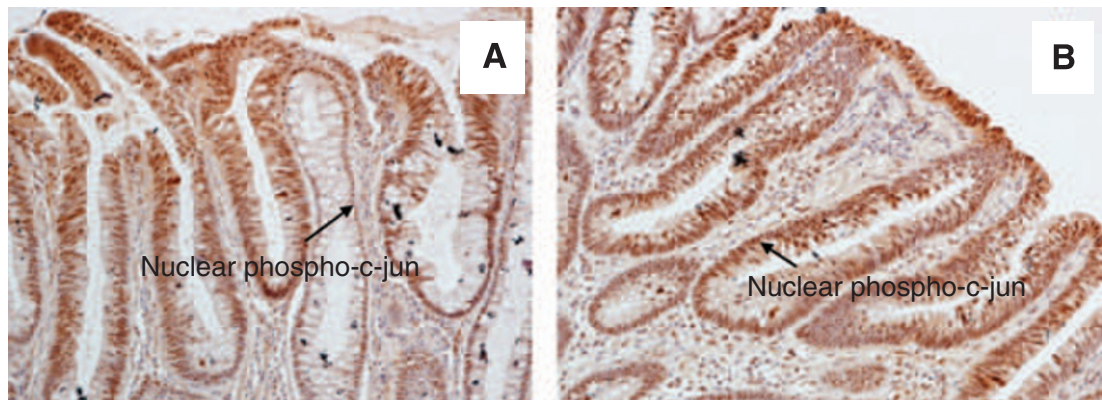

\begin{tabular}{|c|c|c|c|c|c|c|c|c|}
\hline Samples & \multicolumn{2}{|c|}{ sFRP1 } & \multicolumn{2}{c|}{ NKD1 } & \multicolumn{2}{c|}{ c-myc } & \multicolumn{2}{c|}{ FZD3 } \\
\hline $\begin{array}{c}\text { P-c-jun } \\
\text { positive }\end{array}$ & $\begin{array}{c}\text { Direction } \\
\text { of change }\end{array}$ & $\begin{array}{c}\text { Relative } \\
\text { expression }\end{array}$ & $\begin{array}{c}\text { Direction } \\
\text { of change }\end{array}$ & $\begin{array}{c}\text { Relative } \\
\text { expression }\end{array}$ & $\begin{array}{c}\text { Direction } \\
\text { of change }\end{array}$ & $\begin{array}{c}\text { Relative } \\
\text { expression }\end{array}$ & $\begin{array}{c}\text { Direction } \\
\text { of change }\end{array}$ & $\begin{array}{c}\text { Relative } \\
\text { expression }\end{array}$ \\
\hline 1 & $\mathrm{D}$ & 0.01 & $\mathrm{U}$ & 124 & $\mathrm{U}$ & 21 & $\mathrm{U}$ & 13 \\
\hline 2 & $\mathrm{D}$ & 0.08 & $\mathrm{U}$ & 99 & $\mathrm{U}$ & 8 & $\mathrm{U}$ & 18 \\
\hline 3 & $\mathrm{D}$ & 0.10 & $\mathrm{U}$ & 19 & $\mathrm{U}$ & 11 & $\mathrm{U}$ & 74 \\
\hline 4 & $\mathrm{D}$ & 0.14 & $\mathrm{~N}$ & 0.7 & $\mathrm{D}$ & 0.27 & $\mathrm{D}$ & 0.5 \\
\hline 5 & $\mathrm{D}$ & 0.20 & $\mathrm{U}$ & 315 & $\mathrm{U}$ & 4 & $\mathrm{U}$ & 32 \\
\hline 6 & $\mathrm{D}$ & 0.23 & $\mathrm{U}$ & 6 & $\mathrm{~N}$ & 1 & $\mathrm{~N}$ & 1 \\
\hline 7 & $\mathrm{D}$ & 0.63 & $\mathrm{U}$ & 54 & $\mathrm{~N}$ & 1 & $\mathrm{U}$ & 3 \\
\hline 8 & $\mathrm{~N}$ & 0.8 & $\mathrm{~N}$ & 0.73 & $\mathrm{~N}$ & 1 & $\mathrm{U}$ & 2 \\
\hline 9 & $\mathrm{~N}$ & 0.8 & $\mathrm{U}$ & 8 & $\mathrm{U}$ & 6 & $\mathrm{~N}$ & 1 \\
\hline $\begin{array}{c}\text { P-c-jun } \\
\text { negative }\end{array}$ & & & & & & & & \\
\hline 1 & $\mathrm{D}$ & 0.02 & $\mathrm{U}$ & 58 & $\mathrm{~N}$ & 1 & $\mathrm{U}$ & 2 \\
\hline 2 & $\mathrm{D}$ & 0.02 & $\mathrm{U}$ & 16 & $\mathrm{U}$ & 2 & $\mathrm{U}$ & 4 \\
\hline
\end{tabular}

Figure 3 Immunohistochemistry results for phospho-c-jun in FAP adenoma sections. Panels $\mathbf{A}$ and $\mathbf{B}$ show the typical pattern of nuclear staining for phospho-c-jun in adenomas. The table summarises the mRNA expression data for each of the nuclear phospho-c-jun-positive and -negative samples (D, down-regulation; U, up-regulation; $\mathrm{N}$, no change). The relative expression values are calculated by comparing gene expression in adenoma tissue with expression in matched normal mucosa.

be sufficient for the adenoma to limit expression of secreted Wnt antagonists to a level at or below that found in the normal mucosa: although the dominant mechanism for this in sporadic disease is complete silencing, the strong genetic drive of FAP selects for partial suppression. This is likely to be modulated by the distribution of histone marks around the locus (McGarvey et al, 2008) and will require examination in a separate study.

Investigating the outcome of $\beta$-catenin-independent $\mathrm{Wnt}$ signalling in these tumours could show whether similar outcomes are achieved in sporadic and FAP adenomas. No unambiguous markers of these signals have yet been identified in colorectal tumours but a possible response is phosphorylation of c-jun, which can be the result of $\beta$-catenin-independent Wnt signalling in other systems. We have previously reported a correlation between sFRP1 silencing, NKD1 expression and c-jun phosphorylation (Caldwell et al, 2008). In this study, we again found widespread phosphorylation (and nuclear localisation) of c-jun in FAP adenomas and in the cases that showed the highest levels of sFRP1 suppression. FAP adenomas have increased cytoplasmic $\beta$-catenin compared with surrounding normal tissue but lack nuclear $\beta$-catenin (Bläker et al, 2003; Phelps et al, 2009; Anderson et al, 2002; this study). Phelps et al (2009) suggest a model wherein APC loss alone stabilises the levels of cytoplasmic $\beta$-catenin and that subsequent stabilisation and nuclear accumulation of $\beta$-catenin occurs following other secondary events, one of which may be c-jun phosphorylation. did not detect phospho-c-Jun (an indicator of JNK activity) in early adenomatous tissue from FAP patients. This contrasts with our findings where 9 out of 11 FAP adenomas stained positive for nuclear phospho-c-jun. Adenomas from these 11 FAP patients were available for mRNA expression analysis and showed elevated levels of the $\beta$-catenin target gene NKD1 indicating increased $\beta$-catenin-activated transcription.

Cowling et al (2007) showed that $c-m y c$ expression led to a degree of $S F R P 1$ repression in vitro. If this were the case in colorectal tumourigenesis, we might expect a negative correlation between $s F R P 1$ mRNA and $c-m y c$ mRNA in this study. Pearson's correlation analysis of the FAP cohort shows a significant correlation coefficient of 0.78 between $S F R P 1$ down-regulation and NKD1 up-regulation, but there is little correlation between $s F R P 1$ and $c$-myc levels $(r=0.098)$, indicating that $c$-myc does not have a major role in suppression of $S F R P 1$ in these adenomas. Interestingly, Pearson's correlation analysis showed a significant positive correlation coefficient of 0.96 between $c$-myc and FZD3 up-regulation in the FAP series, suggesting that these genes are under similar transcriptional control, which may be the result of Wnt signalling rather than simply $\beta$-catenin stabilisation (Caldwell et al, 2008).

We know that not all adenomas will become cancers and it may be that the molecular heterogeneity we observe in FAP adenomas represents the distinction between adenomas that are more or less likely to become invasive tumours. It is equally possible that, as FAP patients have a large number of adenomas, the heterogeneity represents different stages of adenoma development. The results of our studies however support $s F R P 1$ suppression being an early event in tumourigenesis, as it occurs even in FAP adenomas of $3 \mathrm{~mm}$ or less.

We have shown that most FAP adenomas share the changes in expression of Wnt pathway components that occur in sporadic disease but show a greater degree of heterogeneity, even within a single individual. Although the significance of this is as yet unclear, it may well have an impact on the sensitivity of a subset of tumours to targeted chemopreventive agents. These features could be characterised prospectively in resistant tumours in clinical trials of novel agents.

\section{ACKNOWLEDGEMENTS}

This work was funded by Cancer Research UK and supported by ECMC and UHB Charities. 


\section{REFERENCES}

Anderson CB, Neufeld KL, White RL (2002) Subcellular distribution of Wnt pathway proteins in normal and neoplastic colon. Proc Natl Acad Sci USA 99: $8683-8688$

Bläker H, Scholten M, Sutter C, Otto HF, Penzel R (2003) Somatic mutations in familial adenomatous polyps. Nuclear translocation of betacatenin requires more than biallelic APC inactivation. Am J Clin Pathol 120: $418-423$

Caldwell GM, Jones C, Gensberg K, Jan S, Hardy RG, Byrd P, Chughtai S, Wallis Y, Matthews GM, Morton DG (2004) The Wnt antagonist sFRP1 in colorectal tumorigenesis. Cancer Res 64: 883-888

Caldwell GM, Jones CE, Soon Y, Warrack R, Morton DG, Matthews GM (2008) Reorganisation of Wnt-response pathways in colorectal tumorigenesis. Br J Cancer 98: 1437 - 1442

Caldwell GM, Jones CE, Taniere P, Warrack R, Soon Y, Matthews GM, Morton DG (2006) The Wnt antagonist sFRP1 is downregulated in premalignant large bowel adenomas. Br J Cancer 94: 922 - 927

Chung W, Kwabi-Addo B, Ittmann M, Jelinek J, Shen L, Yu Y, Issa JP (2008) Identification of novel tumor markers in prostate, colon and breast cancer by unbiased methylation profiling. PLoS One 3: e2079

Cowling VH, D'Cruz CM, Chodosh LA, Cole MD (2007) c-Myc transforms human mammary epithelial cells through repression of the Wnt inhibitors DKK1 and SFRP1. Mol Cell Biol 27: 5135-5146

Fearnhead NS, Britton MP, Bodmer WF (2001) The ABC of APC. Hum Mol Genet 10: $721-733$

Hardy RG, Tselepsis C, Hoylands J, Wallis Y, Pretlow TP, Talbot I, Sanders SA, Matthews G, Morton D, Jankowski JAZ (2002) Aberrant P-cadherin expression is an early event in hyperplastic and dysplastic transformation in the colon. Gut 50: 513-519

He B, Reguart N, You L, Mazieres J, Xu Z, Lee AY, Mikami I, McCormick F, Jablons DM (2005) Blockade of Wnt-1 signaling induces apoptosis in human colorectal cancer cells containing downstream mutations. Oncogene 24: 3054-3058

Konishi K, Shen L, Wang S, Meltzer SJ, Harpaz N, Issa JP (2007) Rare CpG island methylator phenotype in ulcerative colitis-associated neoplasias. Gastroenterology 132: $1254-1260$

McGarvey KM, Van Neste L, Cope L, Ohm JE, Herman JG, Van Criekinge W, Schuebel KE, Baylin SB (2008) Defining a chromatin pattern that characterizes DNA-hypermethylated genes in colon cancer cells. Cancer Res 68: 5753-5759

Morin PJ, Sparks AB, Korinek V, Barker N, Clevers H, Vogelstein B, Kinzler KW (1997) Activation of beta-catenin-Tcf signaling in colon cancer by mutations in beta-catenin or APC. Science 275: 1787-1790

Nateri AS, Spencer-Dene B, Behrens A (2005) Interaction of phosphorylated c-Jun with TCF4 regulates intestinal cancer development. Nature 437: 281 - 285 Obrador-Hevia A, Chin SF, González S, Rees J, Vilardell F, Greenson JK, Cordero D, Moreno V, Caldas C, Capellá G (2010) Oncogenic KRAS is not necessary for Wnt signalling activation in APC-associated FAP adenomas. J Pathol 221: 57-67

Phelps RA, Broadbent TJ, Stafforini DM, Jones DA (2009) A two-step model for colon adenoma initiation and progression caused by APC loss. Cell 137: $623-634$

Suzuki H, Watkins DN, Jair KW, Schuebel KE, Markowitz SD, Dong Chen W, Pretlow TP, Yang B, Akiyama Y, Van Engeland M, Toyota M, Tokino T, Hinoda Y, Imai K, Herman JG, Baylin SB (2004) Epigenetic inactivation of SFRP genes allows constitutive WNT signaling in colorectal cancer. Nat Genet 36: 417-422

Yan D, Wallingford JB, Sun TQ, Nelson AM, Sakanaka C, Reinhard C, Harland RM, Fantl WJ, Williams LT (2001) Cell autonomous regulation of multiple Dishevelled-dependent pathways by mammalian Nkd. Proc Natl Acad Sci USA 98: $3802-3807$ 